\section{Book Review}

\section{Healthcare Redesign Tools and Techniques}

\section{Larson JA; New York, NY: Quality Resources, 1997; 176 pages}

Physicians and other healthcare workers have become used to quality assurance programs, total quality management, and continuous quality improvement (CQI). Now it is time to redesign institutions. Process redesign differs from CQI by a radical approach, rather than incremental changes, and focuses on holistic changes. The focus is on reinventing rather than improving the existing system of care. Healthcare Redesign Tools and Techniques covers the principles and pros of redesigning healthcare institutions. It describes tools and techniques for the healthcare setting, based on a book by Hammer and Champy. ${ }^{1}$ The main goal of the redesign is economical and is trig- gered by poor profit of the hospital. Many of the topics are well known to physicians: department rules should not ultimately determine how hospitals should work, but should focus on the patient only.

Several examples are given to support the idea of redesign of healthcare institutions. A highly motivated team is given the opportunity to dream of their optimal way to treat patients. A facilitator coaches the team, and leadership of the chief of the department and the administration is critical.

Measures are financial: "teams should be given very aggressive financial targets for which they are expected to provide sufficient recommendations within just 3 months. No paralysis by analysis or excuses can be allowed."

The book provides details on how one can change the institution. New technology is a key issue. In addition, problems are split in several parts to speed up simple solutions.
The book notes that redesigning may be harmful for people and processes, but emphasis is given to fundamental changes in healthcare institutions.

Some paragraphs are reiterated in the case studies, but provide more applied guidance as to how to redesign the institution.

Physicians need to know about redesigning hospitals, and this book provides ample information on this topic. The approach is radical, and the implementation directive. Therefore, basic knowledge of this topic is important, since it will influence, if not change, how we provide care to our patients.

\section{REFERENCES \\ 1. Hammer M, Champy J. Reengineering the Corporation: A Manifesto for Business Revolution. New York, NY: Harper Collins; 1993.}

Andreas F. Widmer, MD, MS University Hospital Basel, Switzerland

\title{
Epidemiology of $P$ aeruginosa Infection in CF Patients
}

\section{Gina Pugliese, RN, MS Martin S. Favero, PhD}

Recurrent and chronic lower airway infection with Pseudomonas aeruginosa is an important component of cystic fibrosis (CF) pulmonary disease. Different modes of treatment and control of $\mathrm{CF}$ patients have been introduced at the Copenhagen Cystic Fibrosis Centre over the past 20 years and have been associated with improved survival. Treatment consisted of (1) elective antibiotics for 14 days every 3 months to patients with chronic $P$ aeruginosa infection (started in 1976); (2) cohort isolation to prevent cross-infection (patients with $P$ aerugi- nosa were separated from patients without $P$ aeruginosa, starting in 1981); and (3) early intensive treatment with inhaled colistin and oral ciprofloxacin from time of initial $P$ aeruginosa colonization (started in 1989). Frederiksen and coinvestigators found that the annual incidence of chronic $P$ aeruginosa infection decreased significantly, from $16 \%$ to below $2 \%$, after introduction of cohort isolation and early intensive treatment. Furthermore, the time from acquisition of furst $P$ aeruginosa to development of chronic $P$ aeruginosa infection increased significantly, from approximately 1 year to almost 4 years, after introduction of cohort isolation. After introduction of early intensive treatment, the probability of still not having developed chronic $P$ aeruginosa infection 7 years after the first isolation of $P$ aeruginosa was above $80 \%\left(P_{<} .0001\right)$. The authors concluded that the introduction of cohort isolation and early intensive treatment following the initial isolation of $P$ aeruginosa resulted in a reduced incidence and prevalence of chronic $P$ aeruginosa infection.

FROM: Frederiksen B, Koch C, Hoiby N. Changing epidemiology of Pseudomonas aeruginosa infection in Danish cystic fibrosis patients (19741995). Pediatr Pulmonol 1999;28:159166. 